\title{
Physical activity levels and injury prevention knowledge and practice of a cohort of carpentry students
}

Mark Overton BPhty, PGCertPhty, PGDipPhty

Physiotherapist, SouthernRehab, Christchurch

Emily Reynolds BPhty

Physiotherapist, Canterbury District Health Board

Natalie Clark BPhty

Physiotherapist, Nelson Marlborough District Health Board

Haresh Bhana BPhty

Physiotherapist, TeamPhysio, Lower Hutt

Hilda Mulligan BSc, MHealSc, PhD

Senior Lecturer, School of Physiotherapy, CHARR, University of Otago

Karen Elliott MApplSc, DipPhty

Professional practice fellow, Barrington Clinic, School of Physiotherapy, University of Otago

Penny Minnoch BPhty, MSc, PGDipRehab

Professional practice fellow, Barrington Clinic, School of Physiotherapy, University of Otago

\section{ABSTRACT}

The levels of physical activity and knowledge about postures and practices in carpentry students have not been extensively investigated. This study will inform occupational health practitioners about carpentry students' physical activity levels and workplace practices, so that back care and injury prevention education can be included in the curriculum. Data were collected from 51 participants using a questionnaire that asked about levels of physical activity and knowledge and practice for injury prevention. On average 6.4 hours of physical activity was performed weekly outside of work and/or study hours by $86 \%$ of participants. Most participants identified components of a safe lifting technique ('bend knees' 76\%; 'back straight' 45\%). They reported that heavy loads were frequently lifted (51\% often/always lifted weights of $20-30 \mathrm{~kg}$ independently and $69 \%$ rarely using the assistance of a co-worker or lifting device). Although participants had a basic knowledge of common lifting strategies for back care and injury prevention, weights lifted independently were frequently over the deemed safe lifting level. The findings indicate that carpentry students have a basic knowledge of injury prevention and lifting techniques but do not necessarily implement their knowledge into practice.

Overton M, Reynolds E, Clark N, Bhana H, Mulligan H, Elliot K, Minnoch P (2016) Physical activity levels and injury prevention knowledge and practice of a cohort of carpentry students. New Zealand Journal of Physiotherapy 44(2): 84-90. doi: 10.15619/NZJP/44.2.03.

Key words: Injury prevention, Physical activity, Carpentry students, Occupational injury, Education.

\section{INTRODUCTION}

Between September 2010 and June 2011 the city of Christchurch in the Canterbury region of New Zealand was struck by a series of devastating earthquakes that resulted in severe damage to the city's infrastructure and residential areas. To repair this damage Christchurch has undertaken a citywide rebuild plan (Bradley and Cubrinovski 2011). As a result, there has been a large increase in demand for trade workers. This has been reflected by an increase in students enrolling in trade courses at the local institute of technology.

Manual handling is frequently required in a number of occupations, often leading to injury. For example, in the construction industry, the physical demands of the job (constant gripping, prolonged bending, being in awkward/confined spaces and high repetition) can cause injuries in the lower back and upper limbs (Accident Compensation Corporation 2011). Studies have shown that by reducing these physical demands, the prevalence of work-related injuries is also reduced (Owen et al 2002). Construction and carpentry work is highly physical and involves frequent manual handling of equipment and supplies. Such physicality increases workers' risk of acquiring a work-related injury. Injuries can be caused by activities such as lifting heavy loads, vibration, kneeling and reaching activities as well as being in vulnerable positions such as twisting or leaning (Accident Compensation Corporation 2013). Over-exertion also plays a role in work-related injuries, being often associated with workers who push and pull objects using the upper limbs (Ray 
and Teizer 2012). The most common musculoskeletal injuries in manual labour professions are reported in the lower back and upper arm (Muggleton et al 1999).

Educational programmes are a preventative strategy commonly used to reduce work-related injury. Through practice of injury prevention strategies and by keeping fit and healthy, the risk of injury can be reduced (Dong et al 2004). Research has also shown that those who are involved in heavy manual handling are more likely to be active outside of their job, compared to sedentary workers (Kruger et al 2006). The strongest evidence to reduce work-related injury supports the use of multifactorial interventions. These include promoting physical activity, provision of equipment to assist with lifting and manual handling of loads and improving injury prevention practices (Accident Compensation Corporation 2011).

The physical demands of young manual workers (under 25 years) have been reported to be higher than of older workers (over 25 years) due to the different distribution of work tasks as reported in a study by Kjestveit et al (2011). This study noted that the tasks of younger workers included vibration, heavy lifting, repetitive movements and overhead activities, all of which have the potential for injury. The study demonstrated that workers under 25 years of age were more likely to suffer injuries at work compared to their older counterparts (Kjestveit et al 2011). In another study, it was found that upper limb postures during lifting tasks differed between novice and experienced carpenters, with the latter tending to maintain more neutral postures while lifting (Ahmed and Babski-Reeves 2012). It has been suggested that younger workers have a higher level of risk acceptance in their trade due to lack of experience and a higher risk threshold. This risk threshold decreases with more experience and integration into the work environment (Kjestveit et al 2011)

Levels of physical activity and knowledge about postures and practices in carpentry students have not been extensively investigated in New Zealand. With the increased number of carpentry students in the Canterbury region, there could be an increase in work-related injuries in this industry. Our aim therefore was to determine the adequacy of carpentry students' injury prevention knowledge and practice, as well as to investigate their levels of physical activity.

\section{METHODS}

This study was a cross-sectional cohort study, approved by the University of Otago Human Ethics Committee.

\section{Study location, recruitment and participants}

The study was conducted at a local institute of technology in Christchurch, New Zealand. Students enrolled in the Carpentry Diploma course were invited to participate in this study. The course is taught over one year and qualifies the student as an apprentice carpenter. Carpentry consists of mostly manual labour in the construction and maintenance of buildings. The course involves a large practical component with involvement in an apprenticeship throughout the year. There was a potential pool of 80 students. We arranged with the Head of Department at the campus to inform the students about the study and allow them to participate in data collection following one of their lectures. Fifty-five students were present on the allocated day and 51 gave their written consent to participate in the study.

\section{Data collection}

We collected data via a questionnaire that was adapted specifically for this study from a questionnaire developed for trade workers by Vieira and Kumar (2005). The questionnaire obtained data on the participant's demographics, injury prevention knowledge, postures, work practices, physical activity levels, discomfort levels and work-related effort and exertion. The questionnaire also ascertained perceived level of exertion of the job via Borg's 10-point scale of Perceived Exertion (Borg and Kaijser 2006). The level of perceived effort used in the following categories: force; repetition; duration; maintaining one posture; and overall effort during the participant's workday was measured via the 10-Centimetre Visual Analogue Scale (VAS) (Williamson and Hoggart 2005). Also obtained was the level of discomfort perceived in an identified body area(s) at the end of the participant's work day via the 10-point Body Part Discomfort Index (Corlett and Bishop 1976).

Four members of the research team were present for the data collection period. Data were collected under the researchers' supervision over a 30 minute lecture period. Participants were allowed to ask the researchers for clarification regarding any section of the questionnaire if required.

\section{Data analysis}

Raw data were collated into a Microsoft Excel document from which means and standard deviation calculations were derived.

\section{RESULTS}

Forty-eight males and three females participated in this study (mean age, 20 years; age range, 17-50 years; mean weight, $77 \mathrm{~kg}$; mean height, $178 \mathrm{~cm})$. Twenty-five participants identified as being New Zealand European, 15 as Māori, 10 as Samoan and 10 as other (Czech, British, African, Scottish, Filipino), with some participants identifying with more than one ethnicity. Their level of experience varied from being new to a trade (70\%), an apprentice $(24 \%)$ or employed in carpentry $(6 \%)$ and the mean time spent by participants in the carpentry trade was 22 (SD 21) weeks.

Most (84\%) participants reported having had some formal training (type and frequency unknown) on correct techniques for lifting with some receiving training from more than one source. Figure 1 shows the sources where participants identified that they had received formal training on correct lifting techniques. The category of 'other' included 'at the gym', 'posters' and 'sports'. Furthermore, $88 \%$ of participants reported feeling that they had adequate knowledge to protect themselves from a lower back injury. 


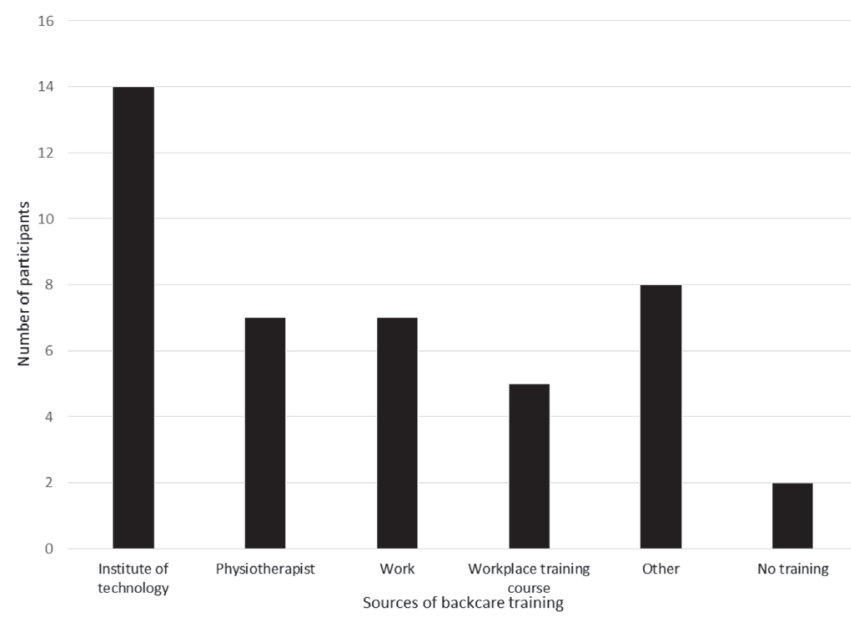

Figure 1: Sources where participants had received formal training on correct lifting

Participants perceived that good lifting techniques included 'bend knees' (76\%), 'back straight' (45\%), 'keep weight close to body' (12\%), 'avoid twisting back while turning' (4\%) and 'other' (27\%). Participants provided examples of 'other' as 'push through your legs', 'transfer weight through your body' and 'squeeze bum'.

Participants also commented on strategies they could practise to prevent a back injury while working. The three most common answers given were 'avoid lifting excessive load' (55\%), 'bend knees' (53\%) and 'keep back straight' (39\%). Multiple answers were permitted in the questionnaire, therefore percentages from the sample total were calculated.

Figure 2 shows the weights participants perceived that they lift independently while working. Forty-four percent of participants reported they would 'never/rarely' lift 40-50 kg and 37\% stated they would 'sometimes'. At $50-60 \mathrm{~kg}, 65 \%$ of participants indicated they would 'never/rarely' attempt lifting this weight independently. However, $8 \%$ of participants reported they would 'often/always' lift 50-60 kg by themselves. In the $60+\mathrm{kg}$ category, $53 \%$ of participants stated they would 'never/rarely' lift this weight independently. The trend lines on Figure 2 show that as the weight of an object increases, the frequency of lifting such a weight decreases.

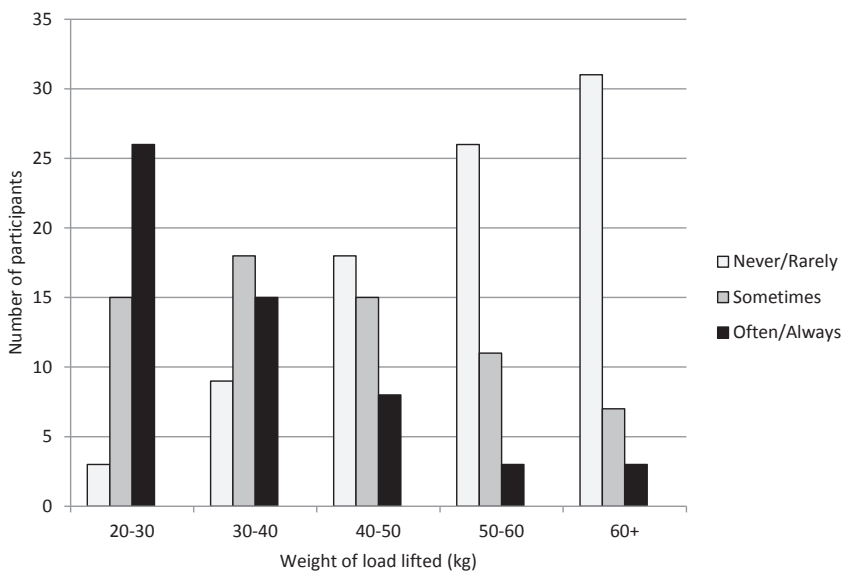

The percentage of participants who used a device or a coworker during lifting tasks indicated they did not generally seek help. Sixty-nine percent of participants reported they 'rarely' got the assistance of a colleague or lifting device. Using assistance 'half of the time' was reported by only $12 \%$ of participants while only $19 \%$ reported getting assistance 'most of the time'. The main reasons for not seeking assistance included lack of coworker availability, limited time or perceived sufficient strength for the task.

Figure 3 shows the devices that participants used to assist them when lifting heavy objects. Some participants reported multiple answers. The results show that most participants who answered this question had knowledge of different devices available to them, with only one participant reporting they were 'unsure'. Machines (cranes, forklifts, elevated work platforms) were the most popular choice with $38 \%$ of participants reporting using these. Manual devices (wheel barrow, trolley, sack barrow) were reported to be used by $35 \%$ of participants, while $21 \%$ reported never using a lifting device.

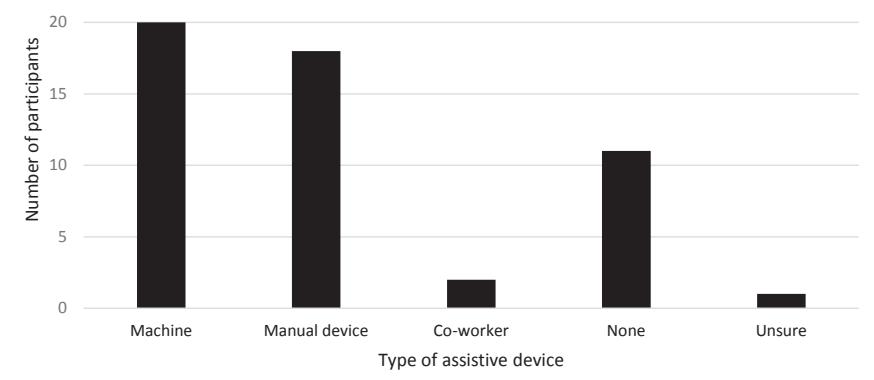

Figure 3: Assistive lifting devices used by participants at their worksite

Table 1 shows the percentage of participants and their usual practices in performing specified work-related activities during an average working day. Twisting when lifting/lowering was reported to be 'often/always' performed by $23 \%$ of participants. Fifty-three percent of participants stated they would 'often/ always' squat while lifting/lowering. Pushing and pulling was reportedly performed 'often/always' by $52 \%$ of participants. Fifty-eight percent of the participants indicated they would 'never/rarely' stoop when lifting/lowering.

Table 2 shows the percentage of participants and their usual practices in performing specified work-related postures during an average working day. Kneeling on one knee was a common posture with 35\% of participants reporting to 'often/always' adopting this position. Standing with trunk rotated and with trunk flexed and rotated was reported as being adopted less often with $69 \%$ of participants reporting to 'never/rarely' be in the latter position.

Figure 2: The perceived weight of loads lifted independently by participants when working 
Table 1: Percentage of time spent performing work-related activities

\begin{tabular}{lccc}
\hline Activity & Never-rarely & Sometimes & Often-always \\
\hline Twisting when lifting and lowering & $53 \%$ & $24 \%$ & $23 \%$ \\
Squat lifting and lowering & $21 \%$ & $26 \%$ & $53 \%$ \\
Pushing and pulling & $18 \%$ & $30 \%$ & $52 \%$ \\
Stooped lifting and lowering & $58 \%$ & $17 \%$ & $25 \%$ \\
\hline
\end{tabular}

Note: Percentage of participants and their usual practices in performing specified work-related activities during an average working day.

Table 2: Percentage of time spent in work-related post

\begin{tabular}{lccc}
\hline Posture & Never-rarely & Sometimes & Often-always \\
\hline Kneeling on one knee & $25 \%$ & $40 \%$ & $35 \%$ \\
Kneeling on both knees & $40 \%$ & $41 \%$ & $19 \%$ \\
Standing with trunk rotated & $52 \%$ & $33 \%$ & $15 \%$ \\
Standing with trunk flexed & $54 \%$ & $33 \%$ & $13 \%$ \\
Standing with trunk flexed and rotated & $69 \%$ & $25 \%$ & $6 \%$ \\
\hline
\end{tabular}

Note: Percentage of participants and their usual practices in performing specified work-related postures during an average working day.

Figure 4 shows the average level of perceived effort while working, measured in centimetres on a VAS out of 10.

Participants were asked to rate their perceived effort in five different categories. The average perceived efforts were: force $(5.9 \mathrm{~cm})$, repetition $(5.8 \mathrm{~cm})$, duration $(5.9 \mathrm{~cm})$, maintaining one posture $(4.7 \mathrm{~cm})$ and overall effort, which was rated the highest $(6.8 \mathrm{~cm})$. Perceived overall effort was assessed using the Borg Scale. The average effort was $5.6 / 10$ which correlates to a 'strong' level of effort.

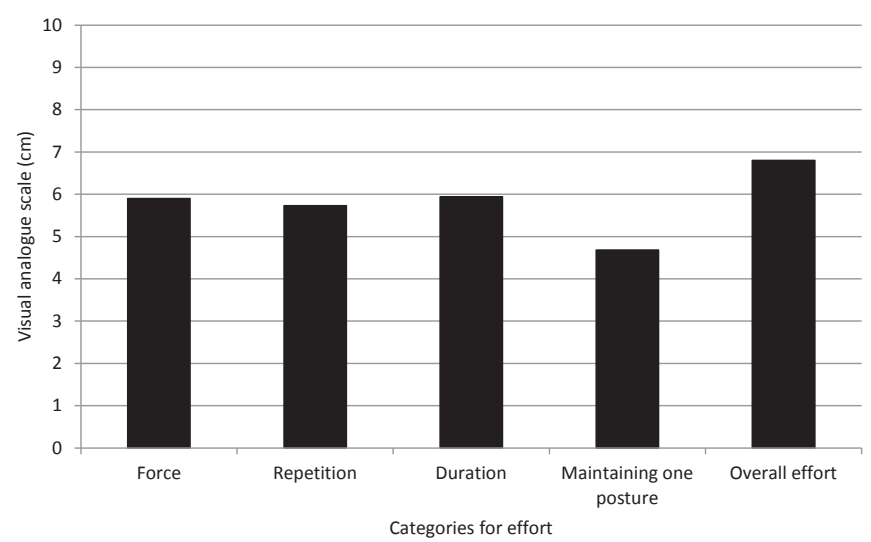

Figure 4: Average perceived effort while working

Participants reported using machinery that exposed them to whole body vibrations on a daily basis. While $58 \%$ of participants stated they were 'never/rarely' exposed, 36\% reported they were 'sometimes' exposed and $6 \%$ indicated they were 'often/always' exposed to whole body vibration.

Figure 5 presents the reported prevalence of discomfort in different body regions at the end of an average working day. The 'lower back' was the most common area for discomfort, reported by $33 \%$ of participants. Discomfort in the 'lower arm' (which comprised the elbow, forearm, wrist and hand) was reported by $25 \%$, while $22 \%$ indicated discomfort in the 'middle back' region. Discomfort in the 'shoulder', 'neck' and 'foot' were each reported by $18 \%$ of participants.

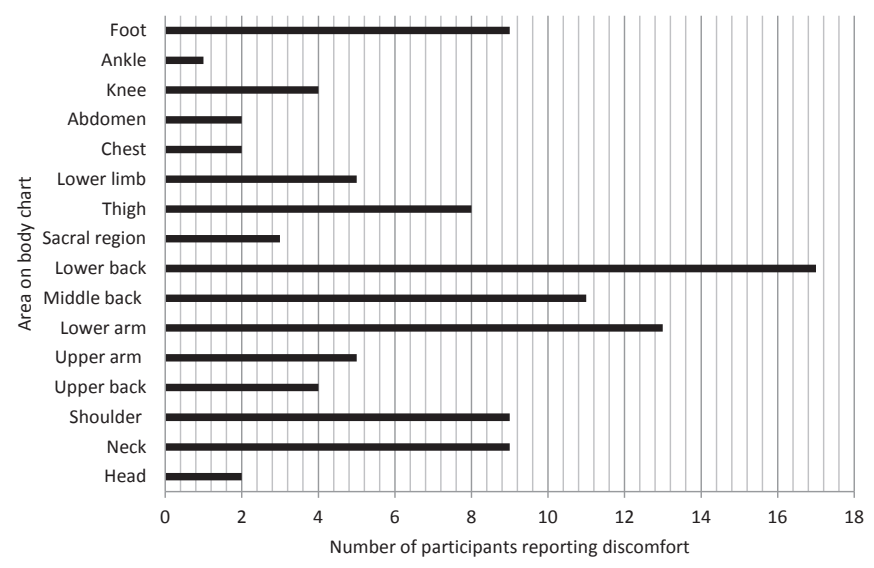

Figure 5: Prevalence of discomfort over specific body regions after an average working day

Figure 6 presents the mean level of discomfort reported by participants at the end of a working day in the respective body areas, using the VAS. The area which was reported as having the highest discomfort level was the 'lower back' $(5.4 \mathrm{~cm})$ followed by the 'lower arm' $(5.1 \mathrm{~cm})$ and 'lower leg' $(5.0 \mathrm{~cm})$. The overall average level of discomfort reported across all body areas was 4.6/10. 


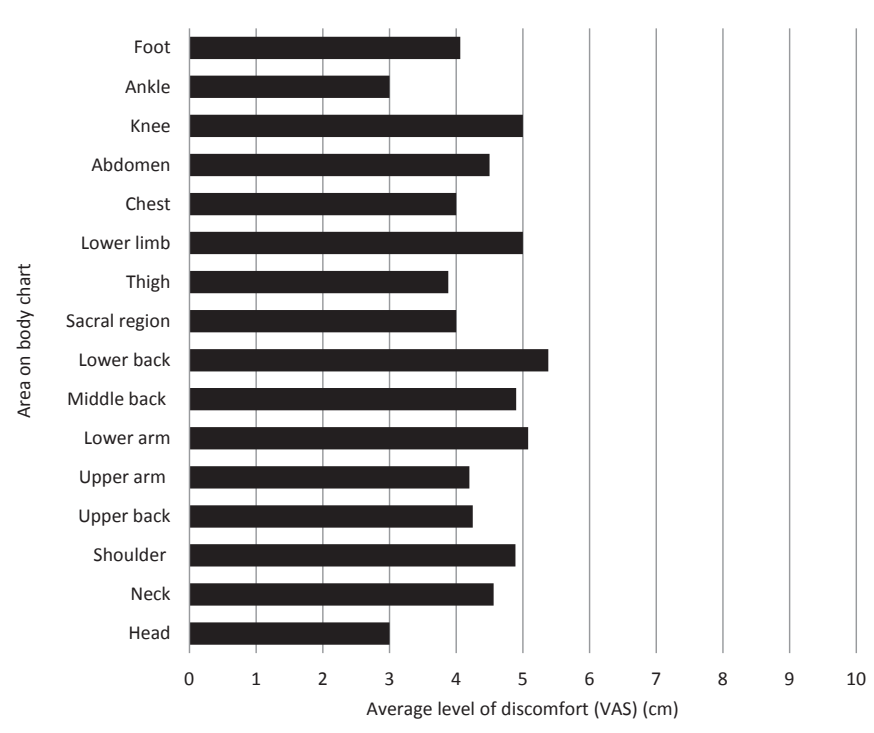

Figure 6: Average level of discomfort over different body regions at the end of a working day

Figure 7 shows the modes of physical activity that participants reported. Most participants (86\%) reported exercising weekly with $43 \%$ being involved in more than one type of exercise. The modes of physical activity were cardio-based such as biking and running (49\%), sports such as rugby and basketball (39\%), gym work such as lifting weights and resistance exercises (31\%) and other miscellaneous activities (6\%). The average duration of weekly physical activity was 6.4 (SD 4) hours per person.

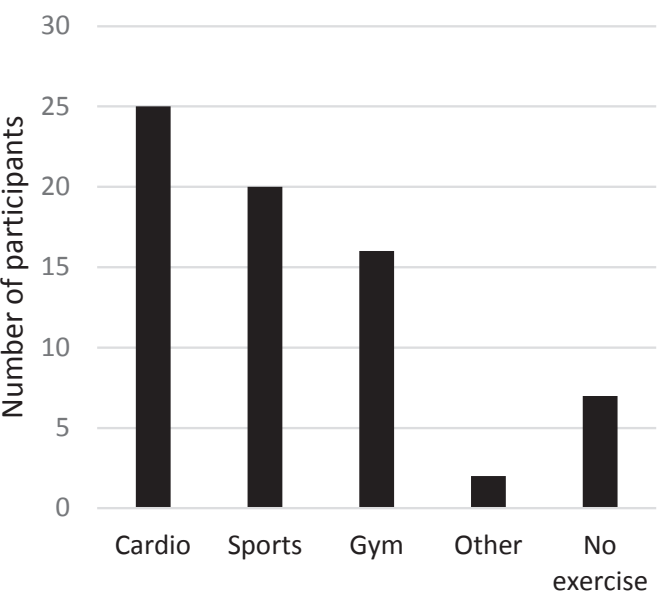

Exercise type

\section{Figure 7: Weekly modes of physical activity reported by participants}

Nine participants (17\%) reported they were smokers, smoking an average of 8.4 cigarettes per day. Eight of the smoking participants reported they regularly participated in exercise with a weekly average of 3.8 hours. The group who smoked were found to be less active than the rest of the participants, with non-smoking participants completing an average of 7.1 hours of exercise per week.

\section{DISCUSSION}

This self-report study was conducted to determine the physical activity, injury prevention knowledge and practices of a new cohort of carpentry students. Results from the study indicated that participants had a basic level of knowledge of common lifting strategies for back care and injury prevention. However, some postures commonly adopted by participants were potentially unsafe and weights lifted independently were frequently over the deemed safe lifting level (Occupational Health Department: Imperial College 2007). Most of the participants reported that they experienced some musculoskeletal discomfort after a work day. On the whole, participants engaged in regular physical activity outside of work although those who smoked were found to be less active than non-smokers.

Recommendations for lifting weights under ideal conditions (upright and straight trunk, weight close to body, firm grip on object with the wrist in a neutral position and a lifting duration of less than one hour per day) are $25 \mathrm{~kg}$ for $95 \%$ of males and $15 \mathrm{~kg}$ for $99 \%$ of females (Occupational Health Department: Imperial College 2007, Gallagher et al 2005). Over half of our participants reported 'often/always' lifting greater than $30 \mathrm{~kg}$. Lifting heavy loads is a risk factor for lower back disorders (Burdorf and Sorock 1997, WorksafeNB 2010) and therefore our participants are potentially at a higher risk of sustaining a lower back injury. Even though the participants acknowledged that lifting heavy weights should be avoided, this behaviour was not observed in their work practice. The gap between knowledge and practice highlights the challenges of incorporating theory into practice. Literature shows that using a lifting device during manual handling has a significant relationship with reducing musculoskeletal symptoms and physical work demands (van der Molen et al 2005). Most participants in our study reported lifting unsafe weights independently, with most reporting that they 'never/rarely' seek the help of a co-worker and $69 \%$ of participants reporting 'rarely' using a lifting device.

Along with weights lifted, participants were also questioned regarding their lifting techniques and the postures they adopted during the work day. Squat lifting was reportedly 'often/ always' performed by over half of the participants. In manual handling education, a strong emphasis has been placed on squatting (back remains as erect as possible while the knees are flexed) while lifting heavy loads (van Dieen et al 1999). However, additional recommendations during squat lifting include lifting loads of moderate weight, restricting load width and eliminating repetitive lifting (Jones and Kumar 2001). Just over $20 \%$ of participants reported they 'often/always' twisted when lifting or lowering, which places them at a higher risk of injury. Twisting can result in a 50\% loss in tensile strength of the structures supporting the spine and is associated with an increased prevalence of back injuries (Jones and Kumar 2001). A consistent relationship has been shown between non-neutral trunk postures and musculoskeletal disorders of the back, with exposure to more than one non-neutral posture further increasing the risk (Punnett et al 1991). More than half of the participants reported they 'often/always' pushed or pulled objects while in an upright position. Pushing or pulling has been found to be consistently associated with shoulder pain and 
when performed excessively, shows a dose-response relationship (Hoozemans et al 2002).

Further back care and safe manual handling education has been identified as important for this cohort of carpentry students. Education should also be provided to their employers to ensure that strategies are being implemented into the workplace as employers are required to eliminate, isolate or minimise hazard as far as is reasonably practicable (Health and Safety at Work Act 2015). Current intervention includes safe manual handling and lifting advice as well as postural education. However evidence to reduce risk of back injury in a cohort such as the one in this study supports a multifactorial intervention to reduce back injury prevalence and pain, targeted at individuals, employers and at policy makers in the industry (Accident Compensation Corporation 2011, Hignett 2003, Oakman et al 2014). Strategies include: risk assessment, education and training, feedback, group problem solving/team building, discussion of goals, assessment systems, hazard registers, physical fitness training and medical examinations (Hignett 2003).

Strategies which target senior staff, employers, educators and policy makers include: equipment provision, equipment evaluation, equipment maintenance, work environment redesign, work organisation changes, changing of policies and procedures, injury monitoring systems and auditing working practices (Hignett 2003, Oakman et al 2014).

Our participants reported the effort to maintain postures to be relatively high $(6.8 / 10)$ and the average perceived exertion was rated as 'strong' on the Borg Scale. Participants therefore perceived their job to require a high amount of effort and energy. Literature shows that maintained static postures can contribute to injury (Jones and Kumar 2001). These prolonged postures can lead to changes in the viscoelastic properties of collagenous tissue. The lengthening of the tissue may cause functional instability, further contributing to work-related injury (Jones and Kumar 2001). As well as static postures, daily exposure to whole body vibration was reported in over one third of our participants. Current research shows that this kind of exposure has a dose-response relationship with back disorders (Xu et al 1997). A higher overall effort is required to maintain a correct posture and these sustained contractions could lead to musculoskeletal disorders in the future. However, literature shows that workers perceive their work as more strenuous when they have chronic lower back pain (Elders and Burdorf 2001). The lower back pain reported by a third of our participants could have affected their level of perceived exertion.

Sustained positions and muscular contractions can often lead to pain and discomfort of body structures, especially the lower back (Burdorf and Sorock 1997). The most common body areas where our participants reported feeling discomfort at the end of a work day were the lower back, mid back, lower arm, shoulder and neck. These findings are supported by other studies (Dimov et al 2000, Holmstrōm et al 1992). A history of lower back pain results in a likelihood of recurrence in the future. A study that investigated this involved 10,000 Danish adolescents. Results found that the participants with lower back pain in the previous year had an odds ratio of 3.5 for recurrence of the pain within the next eight years (Hestbaek et al 2006). Therefore interventions that prevent recurrence of lower back pain have the potential to reduce time off work in the future.

It was interesting to find that the majority of our participants were involved in weekly physical exercise outside of their work hours. What they reported exceeds the American College of Sports Medicine cardiorespiratory exercise recommendations, which is 30 minutes of moderate intensity exercise five times a week (Haskell et al 2007). We also found that those who smoked were less active, exercising for approximately half the time of non-smoking participants. These findings are similar to the inverse relationship between smoking and physical activity identified in literature (Kaczynski et al 2008). Overall our participants were very active and involved in a variety of physical activities despite being at risk for injury and discomfort because of the nature of their work.

A limitation for this study was the sample size and that all participants were studying carpentry. Therefore the results and conclusions should not be generalised to carpentry students in other courses and institutes, nor to other students studying trades. Another limitation includes the potential overestimation in cross-sectional self-reporting questionnaires which could have influenced the results of this study, as there is likely to be a difference between perceived and actual task performance. Overestimation is often linked to the following: male gender, a lower body mass index, finishing full-time education at a younger age and having good general personal health perception (Corder et al 2010). Most of our participants fitted into these categories. Indeed, there are more accurate ways to measure levels of physical activity, for example, via a pedometer (Ainsworth 2009) and it must also be acknowledged that our questionnaire's validity and reliability are yet to be tested. However, this study was the first of its kind to investigate the injury prevention knowledge and practice of first year carpentry students in New Zealand.

\section{CONCLUSION}

This study investigated the knowledge and practice of a cohort of first year carpentry students at an institute of technology in New Zealand. Our study found that participants had knowledge regarding posture and lifting technique but were not necessarily implementing this knowledge into practice. Further studies with a larger sample size, more robust methodology and questionnaire validity testing are recommended. Findings from this study suggest that education on injury prevention strategies with a multifactorial approach be implemented to decrease the risk of workplace injury.

\section{KEY POINTS}

1. A multifactorial intervention aimed at improving workplace injury prevention practices could assist in reducing the likelihood of workplace injury. This could include:

- Educating employers on implementing injury prevention strategies in the workplace.

- Motivating employers to prioritise the health and safety of their staff.

- Teaching employees and employers back injury prevention strategies 
2. Physiotherapists could play a key role in implementing this multifactorial approach due to their expertise in human biomechanics, ergonomics and risk factors for workplace injuries.

\section{PERMISSIONS}

This study was approved by the University of Otago Human Ethics Committee under the reference number 13/048. Informed consent was obtained (both verbally and written) by all study participants.

\section{DISCLOSURES}

This study had no source of funding. No conflict of interest was identified by any party.

\section{ACKNOWLEDGEMENTS}

We would like to thank the carpentry students for participating in the study and Alistair Smith for his help and input.

\section{ADDRESS FOR CORRESPONDENCE}

Mark Overton, SouthernRehab, 29 Byron Street, Sydenham, Christchurch 8240 Telephone: (03) 3668435.

Email: mark.overton@southernrehab.co.nz

\section{REFERENCES}

Accident Compensation Corporation (2013) Preventing and managing discomfort, pain and injury, Wellington, New Zealand. http://www.acc. co.nz/ [Accessed April 9, 2013].

Accident Compensation Corporation (2011) Construction workers: preventing and managing discomfort, pain and injury, Wellington, New Zealand. http://www.acc.co.nz/ [Accessed April 9, 2013]

Ahmed S, Babski-Reeves K (2012) Assessment of upper extremity postures in novice and expert during simulated carpentry tasks. Proceedings of the Human Factors and Ergonomics Society Annual Meeting 56 (1): 11731177. doi:10.1177/1071181312561255.

Ainsworth BE (2009) How do I measure physical activity in my patients? Questionnaires and objective methods. British Journal of Sports Medicine 43 (1): 6-9

Borg E, Kaijser L (2006) A comparison between three rating scales for perceived exertion and two different work tests. Scandinavian Journal of Medicine and Science in Sports 16 (1): 57-69.

Bradley BA, Cubrinovski M (2011) Near-source strong ground motions observed in the 22 February 2011 Christchurch earthquake. Seismological Research Letters 82 (6): 853-865. doi:10.1785/gssrl.82.6.853.

Burdorf A, Sorock G (1997) Positive and negative evidence of risk factors for back disorders. Scandinavian Journal of Work, Environment and Health: 243-256.

Corder K, Griffin SJ, Hardeman W, Sutton S, van Sluiij EM, Watkinson C (2010) Overestimation of physical activity level is associated with lower BMI: a cross-sectional analysis. The International Journal of Behavioral Nutrition and Physical Activity 7: 68

Corlett EN, Bishop RP (1976) A technique for assessing postural discomfort. Ergonomics 19 (2): 175-182. doi:10.1080/00140137608931530.

Dimov M, Bhattacharya A, Lemasters G, Atterbury M, Greathouse L, OllilaGlenn N (2000) Exertion and body discomfort perceived symptoms associated with carpentry tasks: an on-site evaluation. American Industrial Hygiene Association 61 (5): 685-691.

Dong X, Entzel P, Men Y, Chowdhury R, Schneider S (2004) Effects of safety and health training on work-related injury among construction laborers. Journal of Occupational and Environmental Medicine 46 (12): 1222-1228.

Elders L, Burdorf A (2001) Interrelations of risk factors and low back pain in scaffolders. Occupational and Environmental Medicine 58 (9): 597-603.

Gallagher S, Marras WS, Litsky AS, Burr D (2005) Torso flexion loads and the fatigue failure of human lumbosacral motion segments. Spine 30 (20): 2265-2273.
Haskell WL, Lee I, Pate RR, Powell KE, Blair SN, Franklin BA, Bauman A (2007) Physical activity and public health: updated recommendation for adults from the American College of Sports Medicine and the American Heart Association. Medicine and Science in Sports and Exercise 39 (8): 1423.

Health and Safety at Work Act no. 70 (2015) http://www.legislation.govt.nz/ act/public/2015/0070/latest/whole.html [Accessed April 9, 2013].

Hestbaek L, Leboeuf-Yde C, Kyvik KO (2006) Is comorbidity in adolescence a predictor for adult low back pain? A prospective study of a young population. BMC Musculoskeletal Disorders 7 (1): 29.

Hignett S (2003) Intervention strategies to reduce musculoskeletal injuries associated with handling patients: a systematic review. Occupational and Environmental Medicine 60 (9): e6.

Holmstrōm E, Lindell J, Moritz U (1992) Low back and neck/shoulder pain in construction workers: occupational workload and psychosocial risk factors. Spine 17 (6): 663-671.

Hoozemans MJM, van der Beek AJ, Frings-Dresen MHW, van der Woude LHV, van Dijk FJH (2002) Pushing and pulling in association with low back and shoulder complaints. Occupational and Environmental Medicine 59 (10): 696-702. doi:10.2307/27731794

Jones T, Kumar S (2001) Physical ergonomics in low-back pain prevention. Journal of Occupational Rehabilitation 11 (4): 309-319. doi:10.1023/A:1013304826873.

Kaczynski AT, Manske SR, Mannell RC, Grewal K (2008) Smoking and physical activity: a systematic review. American Journal of Health Behavior 32 (1): 93-110.

Kjestveit K, Tharaldsen J, Holte KA (2011) Young and strong: what influences injury rates within building and construction? Safety Science Monitor 15 (2): 1-15.

Kruger J, Yore MM, Ainsworth BE, Macera CA (2006) Is participation in occupational physical activity associated with lifestyle physical activity levels? Journal of Occupational and Environmental Medicine 48 (11): 1143-1148.

Muggleton J, Allen R, Chappell P (1999) Hand and arm injuries associated with repetitive manual work in industry: a review of disorders, risk factors and preventive measures. Ergonomics 42 (5): 714-739.

Oakman J, Macdonald W, Wells Y (2014) Developing a comprehensive approach to risk management of musculoskeletal disorders in non-nursing health care sector employees. Applied Ergonomics 45 (6): 1634-1640.

Occupational Health Department: Imperial College (2007) Moving and handling techniques. Occupational Health Department: Imperial College. http://www3.imperial.ac.uk/pls/portallive/docs/1/15879696.PDF [Accessed April 9, 2013].

Owen BD, Keene K, Olson S (2002) An ergonomic approach to reducing back/shoulder stress in hospital nursing personnel: a five year follow up. International Journal of Nursing Studies 39 (3): 295-302.

Punnett L, Fine LJ, Keyserling WM, Herrin GD, Chaffin DB (1991) Back disorders and nonneutral trunk postures of automobile assembly workers. Scandinavian Journal of Work, Environment and Health: 337-346.

Ray SJ, Teizer J (2012) Real-time construction worker posture analysis for ergonomics training. Advanced Engineering Informatics 26 (2): 439-455.

Van der Molen HF, Sluiter JK, Hulshof CT, Vink P, Frings-Dresen MH (2005) Effectiveness of measures and implementation strategies in reducing physical work demands due to manual handling at work. Scandinavian Journal of Work, Environment and Health: 75-87.

van Dieēn JH, Hoozemans MJ, Toussaint HM (1999). Stoop or squat: a review of biomechanical studies on lifting technique. Clinical Biomechanics 4 (10): 685-696.

Vieira E, Kumar S, Coury H (2005) Questionnaire assessment of problems associated with work-related low back injuries in two steel companies and a hospital. Proceedings of the 10th International HAAMAHA jointly with the 3rd International Ergon-Axia and 1st International Symposium on Theoretical Issues in Ergonomics Science, San Diego, pp. 1-16.

Williamson A, Hoggart B (2005) Pain: A review of three commonly used pain rating scales. Journal of Clinical Nursing 14 (7): 798-804.

WorksafeNB (2010) Ergonomics guidelines for manual handling. http://www. worksafenb.ca/docs/manualedist.pdf [Accessed April 9, 2013].

Xu Y, Bach E, Ørhede E (1997) Work environment and low back pain: the influence of occupational activities. Occupational and Environmental Medicine 54 (10): 741-745. doi:10.2307/27730828. 